\title{
Effect of endotoxin on the hypothalamic-pituitary-adrenal axis in sheep
}

Frédéric Dadoun, Viviane Guillaume, Nicole Sauze, Jean Farisse, Jean-Gabriel Velut, Jean-Christophe Orsoni, Rolf Gaillard ${ }^{1}$ and Charles Oliver ${ }^{2}$

Laboratoire de Neuroendocrinologie Expérimentale, INSERM U 297, Institut Fédératif Jean Roche, Faculté de Médecine Nord, Boulevard Pierre Dramard, 13916 Marseille, ${ }^{2}$ Service d'Endocrinologie, Maladies, Métaboliques et Nutrition, Hôpital Nord, Chemin des Bourrelys, 13915 Marseille Cédex 20, France and ${ }^{1}$ Division d'Endocrinologie et du Métabolisme, CHU Vaudois, CH-1011 Lausanne, Switzerland

(Correspondence should be addressed to C Oliver, Service d'Endocrinologie, Maladies, Métaboliques et Nutrition, Hôpital Nord, Chemin des Bourrelys, 13915 Marseille, Cédex 20, France)

\begin{abstract}
Endotoxin has been shown to stimulate ACTH and cortisol secretion through an action at the hypothalamic level. However, the nature of hypothalamic neurohormones, corticotropin-releasing hormone (CRH) and especially arginine vasopressin (AVP), involved in that regulation is still controversial. The purpose of this study was to determine the effects of an acute i.v. endotoxin administration on CRH and AVP secretion into hypophysial portal blood (HPB). The experiment has been performed in sheep since it is possible to collect HPB and quantify CRH and AVP secretion in this animal under physiological conditions. The release of both peptides into HPB was stimulated by endotoxin injection, the increase in portal AVP being more pronounced than that of CRH. An initial, transient, increase in jugular AVP concentrations was observed, probably due to the activation of magnocellular AVP neurons. In conclusion, our data indicate that the activation of the pituitaryadrenal axis after endotoxin injection is associated with an increased release of both CRH and AVP into HPB. Magnocellular AVP neurons are initially stimulated while parvocellular CRH and AVP neurons are stimulated throughout the experiment.
\end{abstract}

European Journal of Endocrinology 138 193-197

\section{Introduction}

The hypothalamic-pituitary-adrenal (HPA) axis plays an important role in maintaining homeostasis under stressful conditions such as microbial infections and endotoxin shock. Interleukin (IL)-1, IL-6 and tumor necrosis factor- $\alpha$, the major inflammatory cytokines produced under these situations, stimulate the HPA in rats as shown by increased plasma adrenocorticotropin (ACTH) and glucocorticoids and pro-opiomelanocorticotropin mRNA in the anterior pituitary gland (1-3). The regulation of ACTH secretion is a multifactorial process which involves mainly two hypothalamic neurohormones, corticotropin-releasing hormone $(\mathrm{CRH})$ and arginine vasopressin $(\mathrm{AVP})(4,5)$. There is now convincing evidence that in the rat cytokines stimulate hypothalamic $\mathrm{CRH}$ secretion as shown by in vivo $(6,7)$ and in vitro $(8,9)$ studies. However, the influence of cytokines on hypothalamic AVP release remains controversial. Indeed, IL-1 has been shown in vitro to exert no effect on AVP release from hypothalamic fragments $(8,9)$. Other authors have reported no effect of IL-1 on AVP secretion into hypophysial portal blood (HPB) (6), no change in AVP turnover in the median eminence (7) and no effect on the activity of electrophysiologically identified AVP neurons (9). In contrast, other in vivo experiments support a stimulating action of cytokines on AVP release. Indeed, Whitnall et al. (10) have reported that IL-1 deplete secretory vesicles at the level of the paraventricular nucleus (PVN) parvocellular neurons, not only from AVP-deficient CRH neurons but also from AVP-expressing CRH neurons (10). In addition, peripheral administration of IL-1 evokes AVP rise in systemic plasma $(11,12)$ and in perifusates of hypothalamus (13). In the latter studies, the stimulation of AVP release probably occurs at the level of magnocellular neurons of the PVN. Thus, although the effect of endotoxin administration on the stimulation of $\mathrm{CRH}$ neurons has been well established, its effect on AVP neurons remains controversial. AVP may play an important role in stress adaptation by its action on the pituitary gland and also through its peripheral action on vasoconstriction. Therefore, it was of interest to evaluate AVP secretion in portal as well as in systemic blood.

During the past few years, a method for measuring CRH and AVP in HPB under physiological conditions has been validated in conscious, unrestrained sheep $(14,15)$. In this species, the ACTH-releasing potency of AVP has been reported higher (16) or similar (17) to that of $\mathrm{CRH}$. Both peptides act synergistically for 
releasing ACTH (18) and have been involved in the physiological response of ACTH and cortisol to stress $(19,20)$. Using this method, we have directly measured CRH and AVP secretion into HPB after intravenous injection of endotoxin. Endotoxin, a potent stimulator of the immune system, is a lipopolysaccharide (LPS) found as a principal component of Gram-negative bacteria, the main mediator of septic shock. We have also measured AVP levels in jugular plasma (as an index of the secretion of magnocellular AVP neurons) in order to determine if magnocellular AVP neurons are activated by the immune challenge.

\section{Materials and methods}

\section{Animals and surgery}

The experiments were carried out on five 9- to 11month-old Merinos Alps rams (45 kg body weight). The experimental protocol was approved by the Ethical Committee on Animal Studies of the University of AixMarseille II. The rams were prepared for portal blood
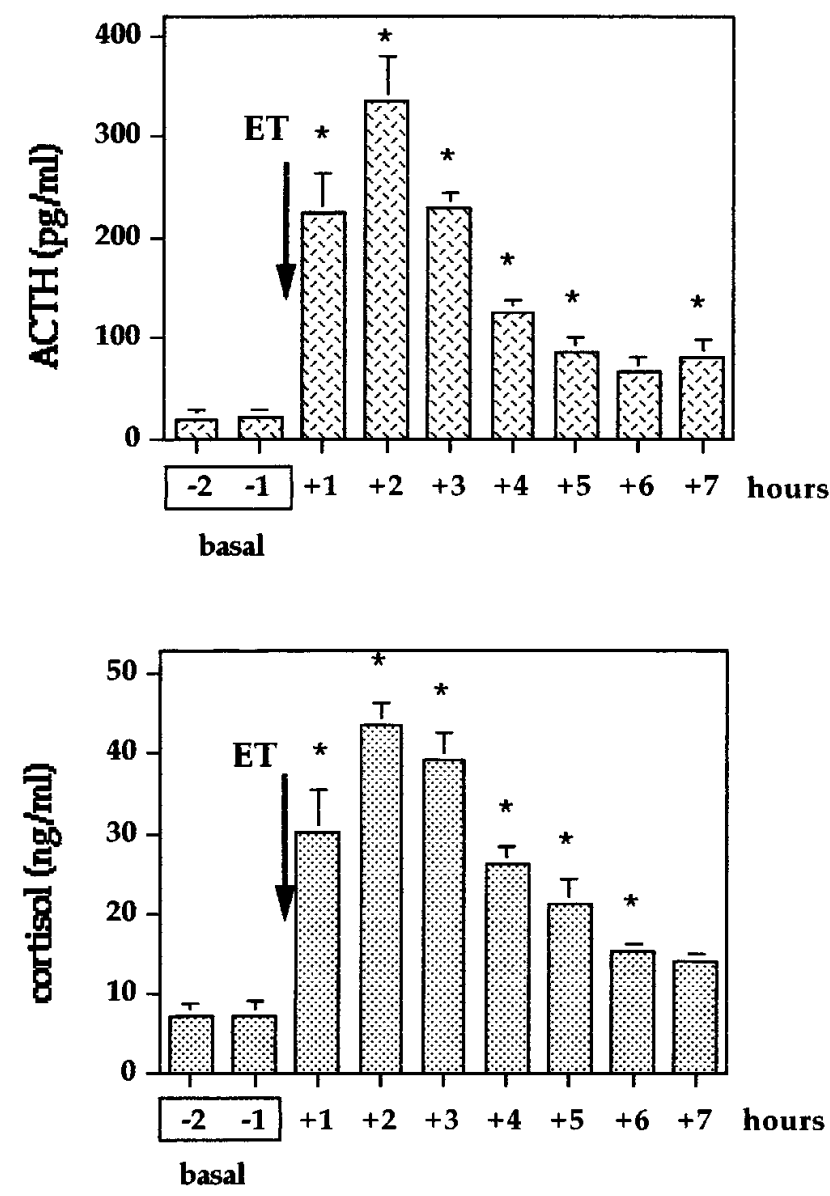

Figure 1 Effect of endotoxin (ET) injection ( $400 \mathrm{ng} / \mathrm{kg}$ i.v.) on mean ( \pm S.E.M.) hourly plasma ACTH and cortisol levels in sheep $(n=5)$. ${ }^{*} P<0.01$ vs basal ACTH and cortisol levels. sampling under general anesthesia, as previously described $(15,21)$. A twin cannula was implanted through the transnasal route in front of the long portal vessels, above the anterior pituitary gland. After 10-12 days, catheters were inserted into the jugular veins of two animals, placed side-by-side in two
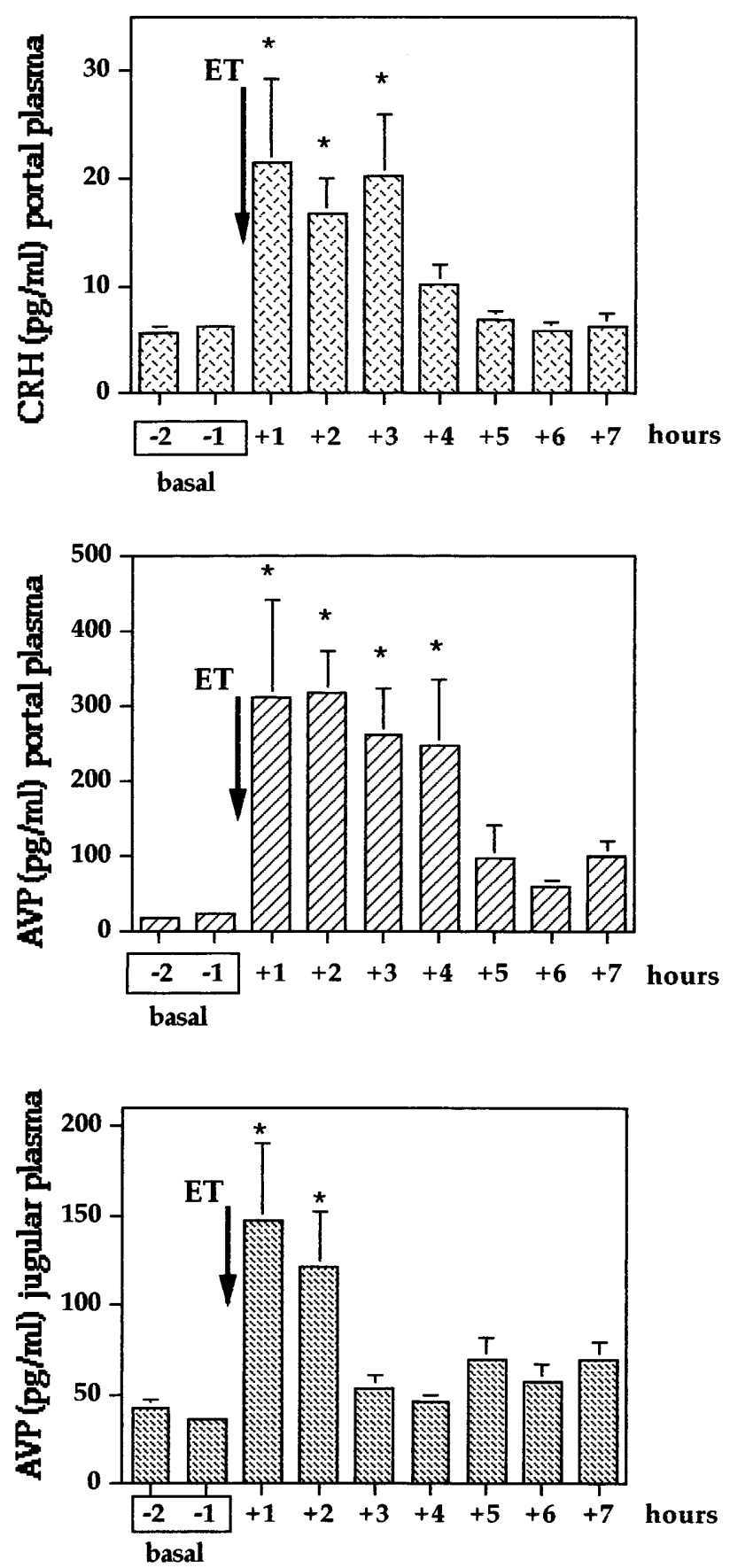

Figure 2 Effect of endotoxin (ET) injection (400 ng/kg i.v.) on mean ( \pm S.E.M.) hourly CRH and AVP levels in HPB, and AVP levels in jugular plasma $(n=5)$. * $P<0.01$ vs basal portal $\mathrm{CRH}$ and AVP and jugular AVP levels. 
small pens on the floor; $24 \mathrm{~h}$ later, at $0600 \mathrm{~h}$, a needle was inserted into the upper cannula to create a lesion of hypophysial portal vessels, and the resulting portal blood was collected through the lower cannula. One jugular catheter was used for injection of heparin (25000 IU at the beginning, followed by $5000 \mathrm{IU}$ every $30 \mathrm{~min}$ ) and endotoxin; the other was connected to a peristaltic pump and used for collection of peripheral blood. Paired samples of portal (0.8$1.2 \mathrm{ml}$, depending on the animals) and jugular blood $(2.0 \mathrm{ml})$ were collected using a peristaltic pump every $10 \mathrm{~min}$ for $8 \mathrm{~h}$.

\section{Experimental procedures}

Endotoxin (Escherichia coli 055: B5: Sigma, St Louis, MO, USA) was reconstituted in phosphate-buffered saline with $0.1 \%$ BSA to a stock concentration of $0.1 \mu \mathrm{g} / \mu \mathrm{l}$. Endotoxin was administered by a bolus injection (400 ng/ $\mathrm{kg}$ ) in $2 \mathrm{ml}$ saline through the jugular cannula, followed by $5 \mathrm{ml}$ saline as previously described (22). Jugular and portal blood were collected during the $2 \mathrm{~h}$ period preceding endotoxin or saline injection and during the subsequent $6 \mathrm{~h}$. Blood samples were immediately centrifuged at $4{ }^{\circ} \mathrm{C}$ for $10 \mathrm{~min}$ and the resulting plasma was stored at $-20^{\circ} \mathrm{C}$ until assayed.

\section{Assays}

All hormone measurements were performed in the same assay using previously described extraction and radioimmunological techniques (23). The intra-assay coefficients of variation within the measurement range of each assay were: CRH, 6\%; AVP, 5.5\%; ACTH, 5\%; and cortisol $4.7 \%$. The limits of detection of the assays were $5 \mathrm{pg} / \mathrm{ml}$ for $\mathrm{CRH}$ and AVP, $10 \mathrm{pg} / \mathrm{ml}$ for ACTH, and $0.5 \mathrm{ng} / \mathrm{ml}$ for cortisol.

\section{Statistical analysis}

The mean hourly plasma hormone concentrations were calculated for the period of basal secretion and the period following endotoxin administration. Results are expressed as the means \pm s.E.M. Data were compared by analysis of variance followed by Fisher's test using a computerized statistical program (Statview 512, Brain Power Inc., Calabasas, CA, USA).

\section{Results}

The i.v. administration of endotoxin at the dose of $400 \mathrm{ng} / \mathrm{kg}$ led to increased respiration, intermittent cough and diarrhea. High fever $\left(41-42^{\circ} \mathrm{C}\right)$ was recorded in all animals and lasted for $6 \mathrm{~h}$. Mean plasma ACTH and cortisol levels increased rapidly and significantly. The maximum increase was reached for both hormones during the second hour, with a 10- and 4.5-fold increase for ACTH and cortisol respectively (Fig. 1). CRH and AVP release into HPB were both stimulated by endotoxin administration. The mean portal CRH levels increased rapidly with a peak during the first hour. $\mathrm{CRH}$ levels remained high during the first $3 \mathrm{~h}$ and then returned to initial values. The stimulation of AVP release was much more pronounced. High levels were already reached within the first hour. Then, AVP levels were still high during the next $3 \mathrm{~h}$, before decreasing rapidly to levels which were still moderately higher than basal values. Jugular AVP levels increased after endotoxin administration; the increase was rapid and transient, lasting for only $2 \mathrm{~h}$ (Fig. 2). Figure 3 shows a typical profile of ACTH and cortisol in peripheral blood and Fig. 4 a typical profile of $\mathrm{CRH}$ and AVP portal levels and jugular AVP in the same representative animal.

\section{Discussion}

Our data indicate that, in the sheep, acute parenteral administration of endotoxin stimulates ACTH and cortisol secretion and the release of $\mathrm{CRH}$ and AVP into HPB. The pattern of stimulation of AVP release into the peripheral circulation is different from that into HPB, being transient and limited to the first $2 \mathrm{~h}$. The source of AVP measured in jugular blood or HPB is probably different. Indeed, peripheral AVP is secreted by the posterior pituitary gland and reflects the activity of magnocellular neurons in
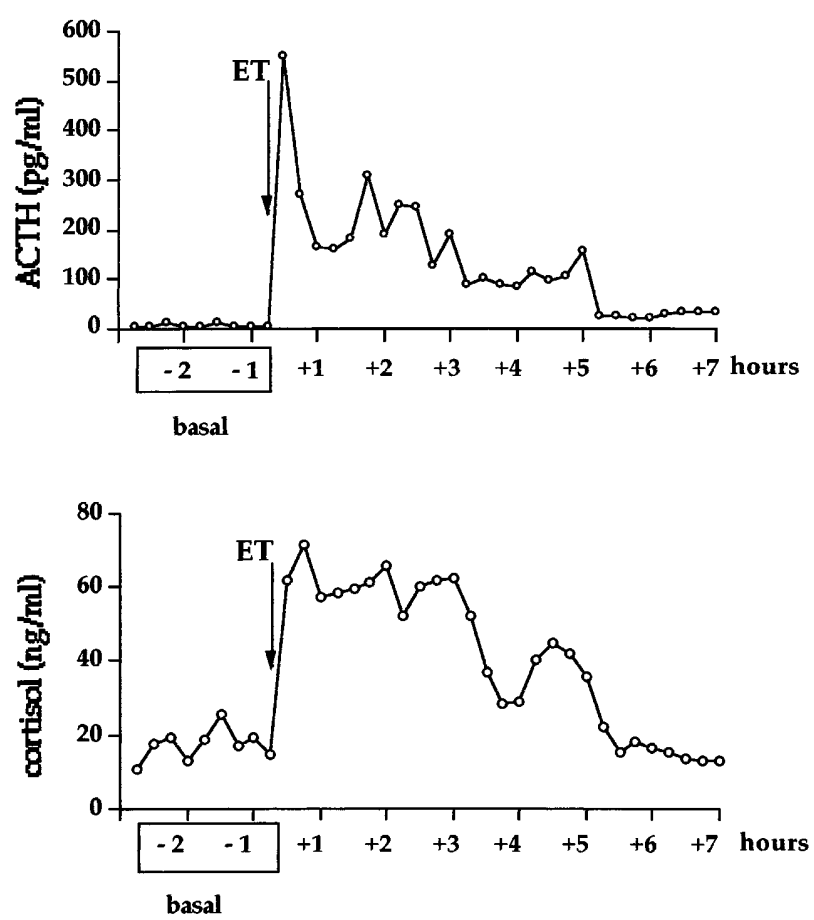

Figure 3 Effect of endotoxin (ET) injection ( $400 \mathrm{ng} / \mathrm{kg}$ i.v.) on jugular plasma ACTH and cortisol levels in one representative animal. 
the PVN and supraoptic nucleus (5). AVP in hypophysial portal vessels originates mainly from the parvocellular part of the PVN, although the contribution of magnocellular neurons to portal AVP cannot be excluded $(24,25)$. The analysis of the pattern of jugular and portal AVP levels following endotoxin administration suggests that magnocellular AVP neurons are rapidly and transiently activated and that the parvocellular portion of the PVN accounts mainly for the increased AVP levels in portal blood after the third hour.

The temporal variations in the activation of the different cellular groups should be better defined by in situ hybridization for hypothalamic CRH and AVP mRNA. However, studies on CRH and AVP cellular localization in ovine hypothalamus are rather limited and no information is yet available on AVP and CRH co-localization in this species. Using this technique in the rat, the activity of
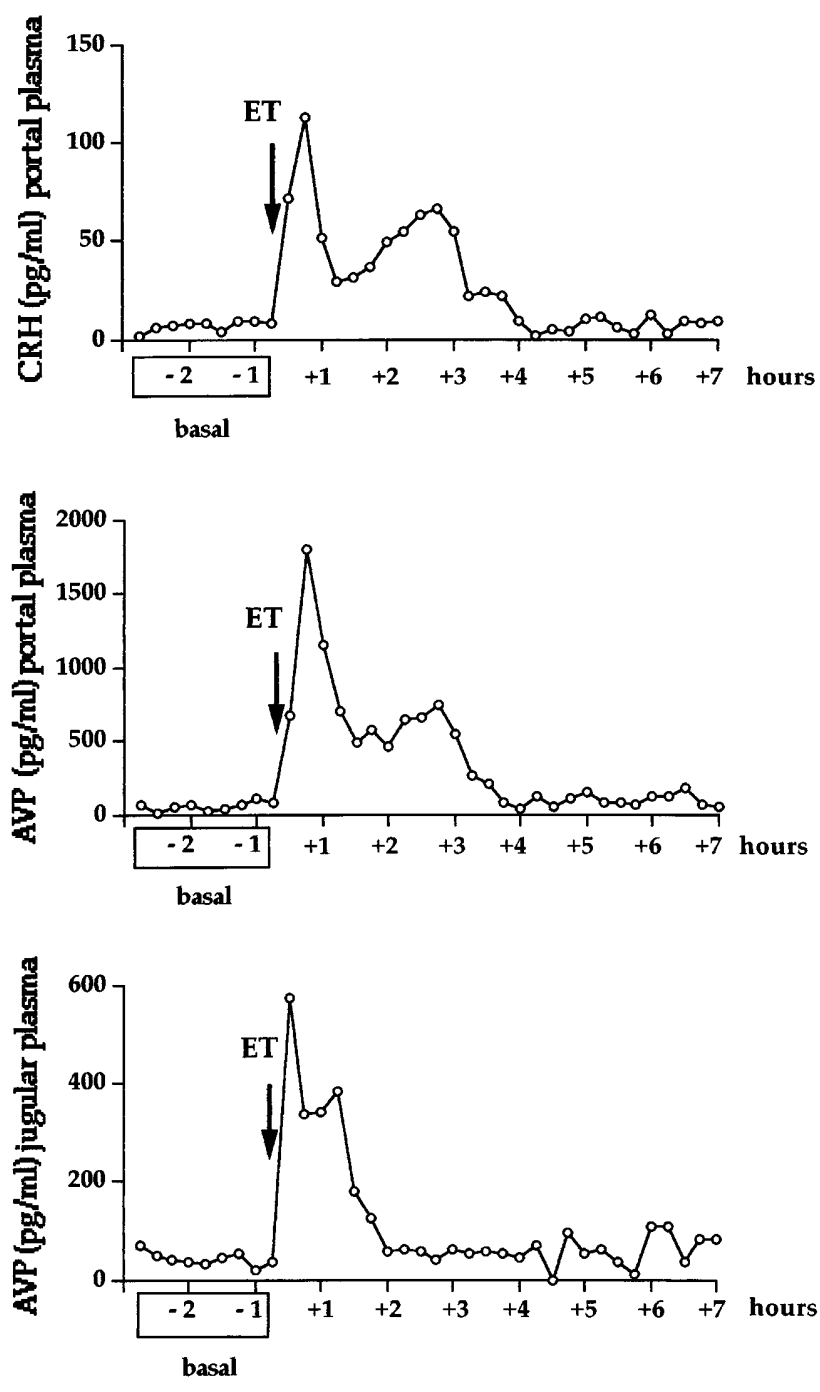

Figure 4 Effect of endotoxin injection ( $400 \mathrm{ng} / \mathrm{kg}$ i.v.) on $\mathrm{CRH}$ and AVP levels in HPB and AVP concentrations in jugular plasma in one representative animal. neurons of the parvocellular portion of the PVN expressing $\mathrm{CRH}$ and AVP has been shown to increase after endotoxin administration. However, in the same animals, there was no evidence for the activation of the magnocellular part of the PVN. An expression of c-fos was detected in magnocellular neurons of the PVN, but the transcript was localized mainly in oxytocin neurons and only in few AVP cells (26). In conscious sheep, the intravenous administration of LPS is accompanied by a significant upregulation of $c$-fos and IL- $1 \beta$ mRNA in the choroid plexus, c-fos $\mathrm{CRH}$ and oxytocin mRNA in the PVN and c-fos mRNA in the supraoptic nucleus. There was no clear upregulation of AVP mRNA in the PVN or supraoptic nucleus (27). However, it is generally accepted that endotoxin injection is followed by an increased production of humoral and hypothalamic cytokines which have been shown to stimulate the HPA axis. A stimulating action of cytokines at the level of AVP magnocellular neurons has been observed in intact (1113) and adrenalectomized rats (28) as well as in humans (29). Indeed, the stimulation of AVP release into the peripheral circulation in both species has been attributed to the activation of magnocellular neurons since this population of hypothalamic neurons is considered to be the source of AVP in the general circulation. Thus, our results are in good agreement with those previous in vivo studies performed in rat and humans. The physiological importance of AVP from magnocellular hypothalamic neurons is still unproven. In rats, it has been possible to induce chronic hyponatremia and inhibit magnocellular hormone secretion while activation of parvocellular neurons appears to be unaffected (30). Under such condition, the stimulation of ACTH secretion induced by either stress or hypertonic saline injection is reduced, indicating that it is partially mediated by magnocellular AVP (31). Similar data have been observed in neurolobectomized rats (32).

In summary, we have observed that the parenteral administration of endotoxin stimulates the hypothalamic release of $\mathrm{CRH}$ and AVP into the HPB. The simultaneous determination of peripheral and portal AVP suggests that AVP secreted by magnocellular neurons increases transiently, shortly after endotoxin administration.

\section{Acknowledgements}

The authors thank Ms G Belpassi and R Quérat for their excellent secretarial assistance. Human synthetic ACTH was provided by the NIDDK Hormone Distribution Program. The Swiss National Science Foundation (Grant 31.00-039.749;93) is acknowledged for its support to R G.

\section{References}

1 Harbuz MS \& Lightman S. Stress and the hypothalamopituitary-adrenal axis: acute, chronic and immunological activation. Journal of Endocrinology 1992134 327-339. 
2 Imura $\mathrm{H} \&$ Fukata J. Endocrine-paracrine interaction in communication between the immune and endocrine systems. Activation of the hypothalamic-pituitary-adrenal axis in inflammation. European Journal of Endocrinology 1994130 32-37.

3 Gaillard RC. Neuroendocrine-immune system interactions. The immune-hypothalamo-pituitary-adrenal axis trends. Endocrinology and Metabolism 19945 303-309.

4 Antoni FA. Hypothalamic control of adrenocorticotropin secretion: advances since the discovery of 41-residue corticotropinreleasing factor. Endocrine Reviews 19867 351-378.

5 Antoni FA. Vasopressinergic control of pituitary adrenocorticotropin secretion comes of age. Frontiers in Neuroendocrinology $19931476-122$.

6 Sapolsky R, Rivier C, Yamamoto G, Plotsky P \& Vale W. Interleukin-1 stimulates the secretion of hypothalamic corticotropin releasing factor. Science $1987238522-524$

7 Berkenbosch F, Van Oers J, Del Rey A, Tilders F \& Besedovsky H. Corticotropin releasing factor-producing neurons in the rat activated by interleukin-1. Science 1987238 524-526.

8 Spinedi E, Hadid R, Daneva T \& Gaillard RC. Cytokines stimulate the CRH but not the vasopressin neuronal system: evidence for a median eminence site of interleukin-6 action. Neuroendocrinology $19925646-53$.

9 Saphier D \& Ovadia H. Selective facilitation of putative corticotropin-releasing factor secreting neurons by interleukin1. Neuroscience Letters 1990114 283-288.

10 Whitnall MH, Perlstein R-S, Mongey EH \& Neta R. Effects of interleukin-1 on the stress-responsive and -nonresponsive subtypes of corticotropin-releasing hormone neurosecretory axons. Endocrinology 1992131 37-44.

11 Naito Y, Fukata J, Shindo K, Ebisui O, Murakami N, Tominaga T et al. Effects of interleukins on plasma arginine vasopressin and oxytocin levels in conscious, freely-moving rats. Biochemical and Biophysical Research Communications 1991 174 1189-1195.

12 Landgraf R, Neuman I, Holsboer F \& Pittman QJ. Interleukin-1 $\beta$ stimulates both central and peripheral release of vasopressin and oxytocin in the rat. European Journal of Neuroscience 19957 $592-598$.

13 Watanabe $\mathrm{H}$ \& Takebe K. Effect of intravenous administration of interleukin-1-beta on the release of prostaglandin E2, corticotropin-releasing factor, and arginine vasopressin in several hypothalamic areas of freely moving rats: estimation by push-pull perfusion. Neuroendocrinology $1994608-15$.

14 Clarke IJ \& Cummins JT. The temporal relationship between gonadotrophin releasing hormone (GnRH) and luteinizing hormone $(\mathrm{LH})$ secretion in ovariectomized ewes. Endocrinology 198211 1737-1739.

15 Locatelli A \& Caraty A. Approche transnasale du système portehypophysaire chez le bélier: application á l'étude des neurosécrétions. Sciences et Techniques de l'Animal de Laboratoire 1987 $12185-190$

16 Familari M, Smith AI, Smith R \& Funder JW. Arginine vasopressin is a much more potent stimulus to ACTH release from ovine anterior pituitary cells than ovine corticotropin-releasing factor. I. In vitro studies. Neuroendocrinology $198950152-157$.

17 Mc Farlane A, Coghlan J, Tresham J \& Wintour EM. Corticotropinreleasing factor alone, but not arginine vasopressin alone, stimulates the release of adrenocorticotropin in the conscious intact sheep. Endocrinology 1995136 1821-1827.

18 Vale W, Vaughan J, Smith M, Yamamoto G, Rivier J \& Rivier C. Effect of synthetic ovine corticotropin-releasing factor, glucocorticoids, catecholamines, neurohypophysial peptides, and other substances on cultured corticotropic cells. Endocrinology $19831131121-$ 1131.

19 Guillaume V, Conte-Devolx B, Magnan E, Boudouresque F, Grino $\mathrm{M}$, Cataldi $\mathrm{M}$ et al. Effect of chronic active immunization anti-corticotropin-releasing factor on the pituitary-adrenal function in the sheep. Endocrinology 1992130 2291-2298.

20 Guillaume V, Conte-Devolx B, Magnan E, Boudouresque F, Grino M, Cataldi $\mathrm{M}$ et al. Effect of chronic active immunization with arginine vasopressin on pituitary-adrenal function in sheep. Endocrinology $19921303007-3014$.

21 Caraty A, Grino M, Locatelli A \& Oliver C. Secretion of corticotropinreleasing factor (CRF) and vasopressin (AVP) into the hypophysial portal blood of conscious, unrestrained rams. Biochemical and Biophysical Research Communications 1988155 841-849.

22 Coleman ES, Elsasser TH, Kemppainen RJ, Coleman DA \& Sartin JL. Effect of endotoxin on pituitary hormone secretion in sheep. Neuroendocrinology 199358 111-122.

23 Caraty A, Grino M, Locatelli A, Guillaume V, Boudouresque F, Conte-Devolx B et al. Insulin-induced hypoglycemia stimulates corticotropin-releasing factor and arginine vasopressin secretion into hypophysial portal blood of conscious, unrestrained rams. Journal of Clinical Investigation 199085 1716-1721.

24 Buma P \& Nieuwenhuys R. Ultrastructural demonstration of oxytocin and vasopressin release sites in the neural lobe and median eminence of the rat by tannic acid and immunogold methods. Neuroscience Letters 198774 151-157.

25 Holmes MC, Antoni FA, Aguilera G \& Catt KJ. Magnocellular axons in passage through the median eminence release vasopressin. Nature $1986319326-329$.

26 Rivest S \& Laflamme N. Neuronal activity and neuropetide gene transcription in the brains of immune-challenged rats. Journal of Neuroendocrinology $19957501-525$.

27 Vellucci SV \& Parrott RF. Bacterial endotoxin-induced gene expression in the choroid plexus and paraventricular and supraoptic hypothalamic nuclei of the sheep. Molecular Brain Research 199643 41-50.

28 Chover-Gonzalez AJ, Lightman SL \& Harbuz MS. An investigation of the effects of interleukin- $1 \beta$ on plasma arginine vasopressin in the rat: role of adrenal steroids. Journal of Endocrinology 1994142 361-366.

29 Mastorakos G, Chrousos GP \& Weber JS. Recombinant interleukin-6 activates the hypothalamic-pituitary-adrenal axis in humans. Journal of Clinical Endocrinology and Metabolism 199377 1690-1694.

30 Verbalis JG, Baldurin EP \& Robinson AG. Osmotic regulation of plasma vasopressin and oxytocin after sustained hyponatremia. American Journal of Physiology 1986250 R444-R451.

31 Dohanics J, Hoffman GE \& Verbalis JG. Hyponatremia-induced inhibition of magnocellular neurons cause stressor-selective impairment of stimulated adrenocorticotropin secretion in rats. Endocrinology 1991128 331-340.

32 Fagin KD, Wiener SG \& Dallman MF. ACTH and corticosterone secretion in rats following removal of the neurointermediate lobe of the pituitary gland. Neuroendocrinology $198540352-362$.

Received 18 July 1997

Accepted 7 October 1997 